\title{
Bilingual English-Persian Dictionaries from a Pragmatic Perspective: Labeling in Focus
}

\author{
Azizollah Dabaghi \\ English Department, Faculty of Foreign Languages, University of Isfahan, Iran \\ Email: azizollahd@hotmail.com \\ Zohreh Gharaei \\ Translation Studies, University of Isfahan, Isfahan, Iran \\ Email: zohreh.2003@yahoo.com
}

\begin{abstract}
The advent of pragmatics into language studies has benefited different areas of linguistics, including lexicography, in general and bilingual lexicography, in particular. To integrate pragmatics into dictionaries lexicographers provide their users with sufficient information about style and register or as Yong and Peng (2007) call it "the socio-cultural aspects of language use," and one widely accepted strategy employed by lexicographers is appropriate labeling. This study attempts to investigate the practice of the three most frequently used English-Persian dictionaries in allocation of labels to words with pragmatic peculiarities. In so doing, 282 words with such restrictions were sampled and categorized into four categories to see the treatment of these dictionaries as far as labeling is concerned. To evaluate the treatment of these dictionaries both internal and external criteria have been taken into consideration. The study revealed that the deficiencies in the labeling system of the existing English-Persian dictionaries can be attributed to the (1) low rate of labeling; (2) inaccurate labeling; and (3) inconsistency in the use of labels implemented.
\end{abstract}

Index Terms — pragmatics, bilingual dictionary, style, register, inclusion, labeling

\section{INTRODUCTION}

Bilingual dictionaries can be regarded as means of communication and comprehension between two groups with different languages, world experiences and cultural backgrounds. The development of pragmatics has influenced lexicography and changed the views toward the features of a dictionary with an optimal usability for either comprehension or production purposes. To be successful, a bilingual dictionary should provide the users not only with target language equivalents, but also with some information about the appropriate use of language. Now the question is how to integrate the achievements of pragmatics into the task of lexicography.

Zgusta (1988) enumerates three aspects of representing pragmatics in the existing reference works as (a) cultural setting in dictionaries; (b) equivalence in bilingual dictionaries; (c) definitions in monolingual dictionaries. Apresyan (1988 in Burkhanov, 2003) believes that pragmatic representations in lexicography reflect the speaker's attitude to reality, the message and the interlocutor. Based on Svensén's view (1993), the specification of "the occurrence of the words and their combinations in different dimensions of language" can be regarded as the manifestation of pragmatics in lexicography. He notes that such information should be provided by register and field labels. Kipfer (1984) also links pragmatics to factors such as time, place, language varieties and the relation between addresser and addressee, adding that this kind of lexicographic specification is provided by usage labels. Landau (1989 in Burkhanov, 2003) believes that pragmatic information, including restriction on the use of words which distinguishes between standard language as opposed to non-standard language as well as geographical, social and temporal limitations should be integrated into dictionaries through labels, special notes and qualifications within definitions or equivalents given in dictionaries. Taking the importance of appropriate use of language into consideration, Yong and Peng (2007) confirm the vital role of pragmatics in learner dictionaries as well as general purpose dictionaries, especially the bilingual ones. They also believe that providing the entries in dictionary with an accurate, consistent labeling system for the words with register and stylistic restrictions can be a good way for integrating the achievements of pragmatics into the task of lexicography, in general, and bilingual lexicography, in particular.

As it is evident, labeling, as one inherent part of all dictionaries meeting average requirements of standard norms, is generally accepted as one way for representing pragmatic peculiarities. Even those who believe that labeling should not be the only strategy to show stylistic and register restrictions, like Landau, do not deny the importance of labeling; instead, they think of these strategies as complementary to one another.

When it comes to bilingual dictionaries, such specification can be even more vital. The reason lies in the fact that inappropriate use of language and communication failure mostly happen between people with different cultural backgrounds and languages, and the users of bilingual dictionaries are certainly among this population. Anyway, in spite of the importance of bilingual dictionaries in production, comprehension and translation related purposes and in 
spite of the fact that these dictionaries have a wide range of users in Iran. They suffer from major shortcomings (Qaneifard, 2003; Ahmadian \& Askari, 2008). Qaneifard (2003) refers to some of the reasons leading to the failure in existing bilingual dictionaries. Unfamiliarity of the lexicographers with modern approached to lexicography as well as the lack of any systematic, scientific and realistic criticism are among them. He believes that no attempt has been made to bring the quality of bilingual dictionaries under close examination, and if any criticism with a focus on the deficiencies could be found, it is either subjective or so general that is far from constructive. As a result, the only work the researchers can refer to focusing on the quality assessment of bilingual English-Persian dictionaries is that of Ahmadian and Askari (2008). They have mentioned some of the deficiencies existing in these dictionaries very generally and briefly. The dictionaries they analyzed are "the four popular English-Persian dictionaries," as they put, namely: Aryanpur (1377), Bateni (1369), Jaafari (1383), and Haghshenas (1381). The study is mainly a contrastive one, putting the mentioned dictionaries against one another, and focusing on their shortcomings in three areas of (1) the choice of Persian equivalent; (2) the use of abbreviations; and finally (3) the pronunciations. Then, for each category one or two examples are mentioned to show the failure of the dictionaries in providing the users with sufficient information. Finally, the treatment of the four dictionaries regarding the chosen word is discussed.

Due to the scarcity of the researches conducted in order to assess bilingual English-Persian dictionaries, no work could be found evaluating them from a pragmatic point of view. This study aims at assessing the three most frequently used English-Persian dictionaries in terms of their application of pragmatic information through their labeling system.

\section{DICTIONARY CRITICISM}

One of the aspects of "metalexicography" or academic lexicography is looking at the products of lexicography and subjecting them to rigorous critiques (Jackson, 2002). Dictionary assessment or criticism, like all kinds of evaluation, should be based on a well-defined framework. For dictionaries, there are two possible sources of evaluation, "internal criteria" and "external criteria" (Jackson, 2002). If evaluation is carried out based on the claims a dictionary or the editors make about it, the evaluation is one based on internal criteria. Dictionaries often point out their features, especially the distinguishing ones, in their front matter. They try to show the superiority of them over other existing dictionaries and these all can be regarded as a good basis for dictionary evaluation as these claims are testable. External criteria, on the other hand, in order to criticize dictionaries, take linguistic requirements into account, making use of the application of the related linguistic areas to the task of lexicography.

This study makes attempt to take both internal and external criteria into consideration.

\section{A. Internal Criteria}

Going through both front and back matter of the three dictionaries under investigation, we tried to find their claimed features, as far as labeling was concerned.

Aryanpur in his one-volume Aryanpur Progressive English-Persian Dictionary believes that one of the salient features of the book is "labels that reveal the field to which a word primarily belongs (e.g., "chemistry" or "biology") and the particular limitations of certain words (e.g., "slang" or "vulgar")", adding that being "aware of the importance of bilingual dictionaries in language learning, in translation, in cultural interaction and, ultimately, in international understanding, I have taken pains to make this dictionary as comprehensive and accurate as possible." In the twovolume dictionary, a similar claim regarding labeling is made, and finally, in the Six-Volume Aryanpur Progressive English-Persian Dictionary he claims that in this dictionary many of the words are accompanied with labels for the first time in Iran, so that the users easily understand the subject field of the words as well as the restrictions on their usage.

Haghshenas (2003) and his assistants in compiling the One-Volume Millennium English-Persian Dictionary (Hezaareh) believe:

"this dictionary offers Persian equivalents together with a wealth of dialectal, stylistic, situational, contextual, grammatical and orthographic information. This will, no doubt, enable users to arrive at the most suitable equivalents with the least possible efforts."

They claim they provide the users with a wide range of information, including dialectal information, like "in Britain", "in America", "in Scotland" and etc., stylistic information, like "informal", "formal", "written", "spoken", "literary", "old-fashioned" and etc, pragmatic information like "ironic", "humorous", "offensive" and etc. They also make reference to an article entitled as Bilingual Dictionary (Samei, 2000). They claim that they have followed the principles mentioned there, asking the reviewers to judge their job based on those principles as well as the framework determined in the front matter of the dictionary. In the article lexical adjustment is believed to be at work at different levels: semantic level, grammatical level, pragmatic level and sociolinguistic level. As the last two levels are in line with our study, we elaborate more on them.

With regard to the pragmatic level, some factors such as setting, topic of discussion, the relation between addresser and addressee are all among determining variables leading to different varieties such as formal, informal, literary, offensive, disapproving and humorous. Concerning the sociolinguistic level, different dialects, the currency of the words and the social connotations the words convey are the implications a word might carry. As he believes, since in some cases it is not possible to find a target equivalent having all the implications existing in the source word, bilingual 
lexicographers should think of a way compensating for the nonexistent features and one important way to fulfill this aim is labeling, especially at pragmatic and sociolinguistic levels.

Unfortunately, Bateni and his assistants in the Farhang -e- Pouya's front matter have not provided the users with any information regarding the use of register and stylistic labels.

Mention should be made that both Aryanpur and Hezaareh dictionaries emphasize that the works are based on the latest findings in linguistics, lexicography and lexicology, paving the way for the researchers' review based on external criteria, as well.

\section{B. External Criteria}

Distinguishing between linguistic competence and communicative competence and emphasizing on the importance of the latter, modern linguistics has proved that appropriate use of words and sentences to the context in which they occur is what language learners should acquire. The importance of this distinction in cross-cultural communication is undeniable due to the fact that grammatically correct productions on the part of non-native speakers sometimes turn to be considered inappropriate to the addressee (Yong \& Peng, 2007).

With the rise of pragmatics and sociolinguistics, dictionaries are expected to apply those findings to become more practical for the users. When it comes to bilingual dictionaries this integration is regarded even more crucial because of the important role they play in intercultural production and comprehension. Nowadays, no doubt, one of the principles of lexicography is making use of restrictive labels to show register and stylistic peculiarities of the words (Gove, 1967; Kipfer, 1984; Zgusta, 1988; Apresyan, 1988; Landau, 1989; Svensen, 1993; Landau, 2001; Jackson, 2002; Yong \& Peng, 2007). Yong and Peng (2007) believe the microstructural presentation of a passive bilingual dictionary should go as follows:

Headword $\rightarrow$ pronunciation (IPA) $\rightarrow$ word classes $\rightarrow$ stylistic and register labels $\rightarrow$ translation equivalents, which may be preceded or followed by semantic, cultural and pragmatic glosses $\rightarrow$ SL examples, with TL translation $\rightarrow$ (etymologies: distant or immediate sources)

As it is obvious, stylistic and register labels are indispensable parts of each entry, if the entry is one with these restrictive features. Based on Jackson (2002), such labels may relate to time, dialect, formality, evaluation, status, field or topic. He believes that "the extent to which dictionaries are consistent in using their range of usage labels and how they apply them are matters for the critic to evaluate."

\section{Methodology}

To choose the English-Persian dictionaries serving as the objects of this study, the researchers made use of a simple questionnaire asking 208 B.A. EFL students about the English-Persian dictionary they used. They were chosen from among English students due to their frequent look-up needs. The views obtained from this questionnaire revealed that Aryanpur is the most frequently used dictionary among English students. Hezaareh and Farhang Moaaser -e- Pouya turned out to be the second and third frequently used dictionaries, respectively. That way, the three English-Persian dictionaries were chosen as the objects of this study.

To be more systematic in dealing with pragmatic specifications, the researcher made use of the six-partite classification proposed by Yong and Peng (2007). In this classification words with style and register restrictions are grouped as follow: (1) words that are limited to a particular region; (2) words that have come to English from foreign origin but still not naturalized; (3) words that have special meaning when used in special field or subject; (4) words that are confined to certain time period; (5) words that can suggest particular attitude or evoke particular reactions or feelings on the part of the users; and finally (6) words that have other restricted uses like the ones used in certain dialects, non-standard speech or special social groups. Considering some of the shortcomings of our dictionaries and due to some practicality reasons, we made some modifications in the above classification. For one thing, we excluded the second category from our study because it was difficult for us, non-native English speakers, to decide which word has been naturalized in English and which has not, as our only frame of reference has been monolingual trusted English-English dictionaries. These dictionaries, at times, provide us with the origin of some words coming into English from other languages like Latin or French, but do not give us any information regarding their naturality in English. Another modification we have made is combining the fifth and sixth categories into one category, as there is sometimes no clear cut distinction between the words of these two categories. Besides, the labeling system of the English-Persian dictionaries under investigation is not that much exact and consistent to take such trivial distinctions into consideration. With these modifications, we came up with four categories as explained below.

Reginalisms are the first category of the sampled words in this study. In fact, they are geographical restriction, and we can take this to include both national varieties and regional dialects within a national variety (Jackson, 2002). This category consists of 74 randomly selected words. They include 30 Briticisms, 30 Americanisms, 7 Australianisms and 7 Scottish English words. Such proportion is due to the fact that the rate of inclusion of Briticisms and Americanisms in English-English learner dictionaries is much higher than other regionalisms used in other varieties of English (Buzon, 1979; Grenon-Nyenhuis, 2000; Xu, 2008), and this is also true about bilingual English-Persian dictionaries. Other varieties such as Irish English or Indian English are rarely treated in English-Persian dictionaries, if treated at all. 
The second category of the sampled words consists of those items restricted to specialized fields. To examine the treatment of these bilingual dictionaries with the words restricted to a special field or subject, 30 words were randomly selected. 20 of them were the words used in special subject fields. The words could be legal, medical, biblical and etc. The remaining 10 words were those related to trademarks. Altogether, these words gave rise to our second category.

30 words were selected representing the third category; e.g., words related to certain time periods comprising of 15 old-fashioned and 15 old-use words. Mention should be made that the distinction between these two subcategories is to some extent vague in our bilingual English-Persian dictionaries, while such distinction is well-recognized in the time tested, trusted monolingual English-English dictionaries. For example, the OALD (2000) defines and labels oldfashioned items as those which "are passing out of current use." However, it defines and labels old-use expressions as the ones which "are no longer in current use." For the purpose of this study, as far as labeling in English-Persian dictionaries was concerned, we took a labeling indicating the oldness of the word as appropriate, and disregarded the distinction, because except for Aryanpur, other dictionaries do not draw the distinction at all. The reason for subcategorizing the sampled words of this category as such was to find if these dictionaries have treated them differently. With regard to neologisms, we excluded them from our study because paying attention to the date of the last edition of the chosen English-Persian dictionaries, we could not expect them to include neologisms which are being added to the lexicon of English with an ever increasing rate.

As it was mentioned before, due to the lack of any clear cut distinction between the words of the fifth and sixth categories, they were combined into one category consisting of 148 words. This category includes 40 formal words, 40 informal words, 30 literary words, 8 humorous words, 15 slang words and finally 15 taboo words.

In order to make sure that the chosen words are the ones required to be included in a general dictionary and the claimed social and register restrictions on them are appropriate, two trusted English-English learner dictionaries were used, Longman Dictionary of Contemporary English and Oxford Advanced Learner's Dictionary in this case, as the frame of reference of this study. In fact, all of the selected words are included in both dictionaries and checked to make sure about register and stylistic peculiarities. Then, the sampled words were looked up in the three English-Persian dictionaries for their inclusion as well as labeling rates. To evaluate the dictionaries both internal and external criteria have been taken into consideration.

\section{RESUlTS AND DisCUSSION}

\section{A. The First Category: Words Marked with Special Regions}

As Table 1 indicates, Aryanpur with the highest rate of inclusion of regionalisms (77.02\%), labels only $47.36 \%$ of the regional words it contains and leaves more than half of these words unlabeled. Pouya and Hezaareh which include $75.67 \%$ and $70.27 \%$ of the sampled words, label $16.7 \%$ and $49.15 \%$ of them, respectively. These figures suggest one major deficiency of the dictionaries under study: low rate of labeling; they leave a high percentage of the marked words they contain unlabeled giving the users no chance of perceiving the restrictions.

TABLE 1

INCLUSION AND LABELING RATES OF THE WORDS OF THE $1^{\text {ST }}$ CATEGORY

\begin{tabular}{lccccccc}
\hline Regionalism & \multicolumn{2}{c}{ Aryanpur } & \multicolumn{2}{c}{ Hezaareh } & \multicolumn{2}{c}{ Pouya } \\
& $\underline{\text { Inc. R. }}$ & Lab. R. & $\underline{\text { Inc. R. }}$ & Lab. R. & Inc. R. & $\underline{\text { Lab. R. }}$ \\
\hline Briticisms & 63.33 & 52.63 & 80 & 41.60 & 80 & 4.16 \\
Americanisms & 90 & 33.33 & 56.66 & 52 & 70 & 4.76 \\
Australianisms & 57.14 & 75 & 57.14 & 100 & 71.42 & 40 \\
Scottish Eng. & 100 & 71.42 & 100 & 85.71 & 85.71 & 83.33 \\
\hline Total & 77.02 & 47.36 & 70.27 & 49.15 & 75.67 & 16.07 \\
\hline
\end{tabular}

The treatments of Aryanpur toward Americanisms, and Hezaareh toward Briticisms are also worth considering. A closer look to Table 1 shows that Aryanpur does not include enough of Briticisms (63.33\%), while it has a much higher inclusion rate of Americanisms (90\%). When it comes to labeling, Aryanpur labels only 33.33\% of the Americanisms it contains. The reason might lie in the fact that Aryanpur is mostly based on American English, so the percentage of Americanisms exceeds that of Briticisms and Americanisms are to some extent taken for granted and apparently, that is why many of Americanisms are left unlabeled. But the fact is that this dictionary is not totally an American one, and words of other varieties of English are also observable in it. This necessitates the dictionary to distinguish between these varieties. The same point is true about the treatment of Hezaareh toward Briticisms.

As for the rates of Australianisms and Scottish English words reported in Table 1, one point is noteworthy. The fact is that the rates reported in Table 1 are not good representatives of these items in the three bilingual dictionaries under study. The reason is that these rates are achieved with a sample of only 7 words, as listed in Appendix 1 . As it was mentioned above, only those words have been chosen which are both included and labeled in the monolingual dictionaries which served as our frame of reference, Longman Dictionary of Contemporary English and Oxford Advanced Learner's Dictionary in this case, and these dictionaries rarely include words of varieties other than Americanisms and Briticisms. The fact that we could not sample more words is itself expressive of the inadequate treatment of $L D C E$ and $O A L D$ toward regionalisms other than Americanisms and Briticisms. Xu (2008) came to the 
same conclusion, while studying these items with the prime purpose of examining the practice of the "Big Five" in allocation of the examples to different items. He concluded that "other varieties of English have not received sufficient attention in the "Big Five," either in inclusion and labeling or in exemplification rates. Grenon-Nyenhuis (2000) also believes that dictionaries are biased in treating less dominant cultures and linguistic varieties and do not list all the words that are in usage in a neutral way. Buzon (1979 in Grenon-Nyenhuis, 2000) also believes that dictionaries function as filters. Apparently, the inadequate treatment of these trusted dictionaries toward regionalisms have had negative effects on the practice of English-Persian dictionaries as well, due to the fact that monolingual, time-tested dictionaries are used as primary references of bilingual lexicographers, in general, and English-Persian lexicographers, in particular.

\section{B. The Second Category: Words Marked with Subject Fields}

As the results indicate Aryanpur has the highest rates of entry inclusion (93.33\%) and labeling (71.42\%) among the three dictionaries. Pouya is in the second rank of entry inclusion $(83.33 \%)$, while it has the lowest rate of labeling (32\%). Hezaareh and Pouya have equal rates of entry inclusion $(83.33 \%)$; they differ in their labeling rates, though. Hezaareh, after Aryanpur, with a labeling rate of $48 \%$ is in the second rank, and Pouya with the lowest labeling rate $(32 \%)$ is in the third rank.

TABLE 2

INCLUSION AND LABELING RATES OF THE WORDS OF THE 2ND CATEGORY

\begin{tabular}{|c|c|c|c|c|c|c|c|c|}
\hline Subject field & $\begin{array}{l}\text { Aryanp } \\
\text { Inc. R. } \\
\end{array}$ & $\begin{array}{l}\text { Ir } \\
\text { Lab. R. }\end{array}$ & $\begin{array}{l}\text { Hezaa } \\
\text { Inc. R. }\end{array}$ & $\begin{array}{l}\text { h } \\
\text { Lab. R. }\end{array}$ & $\begin{array}{l}\text { Pouya } \\
\text { Inc. R. }\end{array}$ & Lab. R. & $\begin{array}{l}\text { Total } \\
\text { Inc. R. }\end{array}$ & Lab. R. \\
\hline Technical words & 100 & 65 & 85 & 70.58 & 90 & 44.44 & 91.66 & 60 \\
\hline Trademarks & 80 & 90 & 80 & 0 & 70 & 0 & 76.66 & 30 \\
\hline Total & 93.33 & 71.42 & 83.33 & 48 & 83.33 & 32 & 86.66 & 50.47 \\
\hline
\end{tabular}

While Aryanpur labels $90 \%$ of trademarks, Hezaareh and Pouya do not provide the users with any labels for such words. Table 3 lists the rates of the inclusion and labeling for the words restricted to a special subject field.

\section{The Third Category: Words Marked with Currency}

Table 3 lists the rates of inclusion and labeling for the words marked with currency. As it is shown, the three dictionaries have the highest rate of inclusion for these items (100\%), while they do not function well with regard to labeling these items. Hezaareh which has the highest rate of labeling among the three dictionaries labels only $55.17 \%$ of these words, followed by Aryanpur and Pouya with labeling rates of $37.93 \%$ and $27.58 \%$.

TABLE 3

INCLUSION AND LABELING RATES OF THE WORDS OF THE 3RD CATEGORY

\begin{tabular}{|c|c|c|c|c|c|c|c|c|}
\hline Currency & $\begin{array}{l}\text { Aryanp } \\
\text { Inc. R. }\end{array}$ & $\begin{array}{l}\text { Ir } \\
\text { Lab. R. }\end{array}$ & $\begin{array}{l}\text { Hezaar } \\
\text { Inc. R. }\end{array}$ & $\begin{array}{l}\text { h } \\
\text { Lab. R. }\end{array}$ & $\begin{array}{l}\text { Pouya } \\
\text { Inc. R. }\end{array}$ & Lab. R. & $\begin{array}{l}\text { Total } \\
\text { Inc. R. }\end{array}$ & Lab. R. \\
\hline Old-fashioned & 100 & 13.33 & 100 & 26.66 & 100 & 26.66 & 100 & 22.21 \\
\hline Old-use & 100 & 62.28 & 100 & 85.71 & 100 & 28.57 & 100 & 58.85 \\
\hline Total & 100 & 37.93 & 100 & 55.17 & 100 & 27.58 & 100 & 40.22 \\
\hline
\end{tabular}

The interesting point about words marked with currency is that although our sample words are all the items not in use in today English, the three dictionaries have the highest possible inclusion rate (100\%) for them. It could be regarded as a positive point providing that these dictionaries had also high rates of labeling for these items, while it is not the case. Having high rate of inclusion without appropriate labeling which enables the users to distinguish old words from the words used in current English, misleads them, doubtlessly. This is why it is very important to label old-fashioned and old-used words, if they are to be included in a general purpose dictionary.

\section{The Fourth Category: Words Marked with Special Styles or Attitudes}

With regard to the words marked with a specific style or attitude, formal and literary words have the highest inclusion rate (100\%), but these words are not treated well in Aryanpur and Pouya as far as labeling is concerned (0\%). Informal words have also a rather high rate of inclusion with a total average inclusion rate of $94.16 \%$ in all three dictionaries. Among them Pouya is in the first rank (97.5\%), while it has the lowest labeling rank among the three dictionaries $(15.38 \%)$.

As it is shown in the Table 4, Pouya has the highest inclusion rate of slang words (93.33\%) and the lowest labeling rate of those words (64.28\%). Hezaareh, with a labeling rate of $100 \%$ is in the first rank among the dictionaries. Of course, mention should be made that Hezaareh uses the same labels for informal, slang and taboo words and does not distinguish them in terms of labeling. That is why labeling rates of slang and taboo words are marked with asterisks. Although having $100 \%$ inclusion rate for taboo words, Hezaareh does not provide even one appropriate label for them (0\%). In this case Aryanpur has the highest rate (83.33\%). 
TABLE 4

INCLUSION AND LABELING RATES OF THE WORDS OF THE 4TH CATEGORY

\begin{tabular}{|c|c|c|c|c|c|c|c|c|}
\hline Style and attitude & \multicolumn{2}{|c|}{$\begin{array}{l}\text { Aryanpur } \\
\text { Inc. R. Lab. R. }\end{array}$} & \multicolumn{2}{|c|}{ Hezaareh } & \multicolumn{2}{|l|}{ Pouya } & \multicolumn{2}{|l|}{ Total } \\
\hline Formal words & 100 & 0 & 100 & 72.5 & 100 & 0 & 100 & 24.16 \\
\hline Informal words & 95 & 60.52 & 90 & 80.55 & 97.5 & 15.38 & 94.16 & 52.15 \\
\hline Literary words & 100 & 6.66 & 100 & 23.33 & 93.33 & 0 & 97.77 & 9.99 \\
\hline Slang words & 60 & 88.88 & 60 & $100 *$ & 93.33 & 64.28 & 71.11 & 84.38 \\
\hline Taboo words & 87.71 & 83.33 & 100 & $0^{*}$ & 92.58 & 38.46 & 93.43 & 40.59 \\
\hline Humorous words & 87.5 & 0 & 87.5 & 28.57 & 87.5 & 14.28 & 87.5 & 14.28 \\
\hline Total & 96.59 & 30.28 & 92.51 & 55.88 & 95.91 & 14.18 & 95 & 33.44 \\
\hline
\end{tabular}

With regard to words marked with a special style and attitude, it is surprising to see that Aryanpur and Pouya do not have even one label marking formal items. In the view of these dictionaries there is no difference between occur as a formal word and a word like crop up, as far as labeling is concerned. One might claim that labeling is not the only way to show the peculiarities of the words; appropriate translation equivalents in bilingual dictionaries can do the same function. But, the fact is that no two languages have exact lexical overlaps to be reflected by means of translation equivalents. In order for two words to be perfect equivalents in two different languages, they should have semantic, grammatical, pragmatic and sociolinguistic overlaps (Samei, 2000). In many cases it is not possible to find a translation equivalent in the TL, totally representative of the SL word; the equivalent in the TL might overlap with the SL word with regard to the semantic level, but the pragmatic and sociolinguistic implications might differ (Pitrowski, 1994). An example can be the word sagacious, one of our sample formal words which is labeled neither in Aryanpur nor in Pouya, making no difference between this word and a word like wise. The point is that even the translation equivalents they offer do not distinguish between these words, and it is very natural because it might be very difficult to find a Persian equivalent for the word sagacious implying exactly the same pragmatic implications as those in English word sagacious.

Similar problems exist with regard to literary, humorous, slang and taboo words. These are all different aspects of style and attitude, implicit in the words, and taking all these different aspects into consideration is certainly an important step to not only production related purposes -which is not our main concern here, as the dictionaries under investigation are passive dictionaries, aiming at comprehension and translation related purposes (Hartman \& James, 2002) - but also the comprehension of the text in which such words are included. No doubt, comprehension is not achieved only by knowing about the semantic components of the words, but all the overtones, stylistic features, social and cultural information loaded in the words are crucial to the proper understanding of the text. The importance of these factors becomes even more salient if viewed from a translation related perspective, since, there, except for the mere comprehension of these implications, another factor comes also into the play which is the creation of these peculiarities in the TL.

The allocation of labels to some of these subcategories seems to be even more important. A case in point is that of taboo words. A Taboo word as defined by Dictionary of Lexicography (2002) is "a word, phrase or name the use of which is considered unacceptable for social reasons." The $L D C E$ defines these words as the ones people avoid because of being "offensive and embarrassing," and finally based on the $O A L D$, they are "words that many people consider offensive or shocking, for example because they refer to sex, the body or people's race." In bilingual dictionaries where there are certain sociocultural gaps between the two languages, it is very important to warn the non-native users, unaware of negative social implications of such words, against them, as this subcategory is one of the sensitive ones, expected to have the highest possible labeling rate. But, despite the importance of an appropriate labeling system for this category, the results of this study showed that the total labeling rate of the three dictionaries for these items is less than $50 \%$, and it is far from desirable.

Apart from the low labeling rate of these dictionaries for the items discussed above, inappropriate and inaccurate labeling is another deficiency observed in Hezaareh. Hezaareh does not distinguish between informal, slang and taboo words as far as labeling is concerned, and this is very misleading to the users. In fact, the reason why Hezaareh has a labeling percentage of $0 \%$ is not the lack of labeling, but inappropriate labeling, and as Yong and Peng (2007) rightly believe, it is worse to label the words incorrectly than not to label them at all. In this dictionary the word عاميانه is used to mark informal, slang and highly offensive forbidden taboo words.

Table 5 shows the total inclusion and labeling rates and ranks of the three dictionaries under study for all the sampled words. As the results indicate, Aryanpur has the highest total inclusion of the sampled words $(90.84 \%)$, while it has a low labeling rate for these words $(38.11 \%$ ) leaving more than $61.80 \%$ of them unlabeled. Regarding labeling, Hezaareh sits in the first place, with a total labeling rate of 54.95\%. As evident, Pouya has a very low labeling rate. This dictionary does not label more than $82 \%$ of the words with special usage restrictions.

TABLE 5

TOTAL INCLUSION AND LABELING RANKS OF THE THREE DICTIONARIES

\begin{tabular}{l|cccc}
\hline Dictionary & Total Inclusion & Rank & Total Labeling & Rank \\
\hline Aryanpur & 90.84 & 1 & 38.11 & 2 \\
Hezaareh & 82.03 & 3 & 54.95 & 1 \\
Pouya & 85.42 & 2 & 17.85 & 3 \\
\hline
\end{tabular}


In general, the dictionaries under investigation do not seem to follow any systematic procedure for providing words with labels. Another negative point in their labeling system which has been overlooked in our results is the lack of a unified labeling system. For example, Aryanpur in order to show slang words uses labels such as ناخوشايند،خودمانى زننده and, while in its front matter does not provide the users with any information about these labels or the differences among them. Pouya also uses the labels فحش and عاميانه for these words. Hezaareh uses two labels for marking informal words, محاوره anould without distinguishing between them. Mention should be made that these inconsistencies are not limited to the examples mentioned.

\section{CONCLUSION}

Advances made in the area of linguistics, in general and lexicography, in particular, have changed bilingual dictionaries as a mere reference book to a communicative device intending to ease interlingual and intercultural communication, production and comprehension. It is believed that the dictionary related studies can not expect to make substantial progress "unless socio-cultural dimensions are taken into the lexicographic scene, for dictionary making is essentially a socio-cultural behavior" (Yong \& Peng, 2007). One manifestation of the integration of socio-cultural aspects of language into the task of lexicography is to integrate register and stylistic peculiarities of the words into dictionaries. One widely used and accepted way to achieve that aim is making use of appropriate labels to mark such words.

This study aimed at examining the practice of three frequently used English-Persian dictionaries in treating words restricted with pragmatic peculiarities; that is, style and register restrictions. Although the study is far from exhaustive, it revealed the fact that English-Persian bilingual dictionaries have not provided the users with an adequate, accurate and consistent labeling system, and this inadequacy is in contrast with both the lexicographic standards governing dictionaries and the claims they make as to their making use of labels to show particular attitudes as well as limitations on the use of words in particular situations. The study revealed that the deficiencies in the labeling system of the existing English-Persian dictionaries can be attributed to (1) the low rate of labeling; (2) inaccurate labeling; and (3) inconsistency in the use of labels implemented.

\section{APPENDIX}

TABLE 1

WORDS MARKED WITH SPECIAL REGIONS

\begin{tabular}{ll}
\hline Regionalisms & Sample Words \\
\hline Briticisms & $\begin{array}{l}\text { abseil, backcomb, bap, barmy, box junction, cart ridge paper, cheeky, } \\
\text { dicky, don, gazump, git, granny flat, ginormous, hoick, identikit, } \\
\text { invigilate, linctus, lippy, minster, nosy parker, polling day, poof, } \\
\text { question master, quid, raver, singlet, suss, telephonist, wage packet, } \\
\text { whinge }\end{array}$ \\
Americanisms & $\begin{array}{l}\text { absent ballot, auto, baby carriage, back talk, baggage car, bald-faced, } \\
\text { bolo tie, box car, defy, demagogue, dishpan, filbert, flunk, } \\
\text { gonzo journalism, knobbly (knobby), lawn bowling, line, liquor store, } \\
\text { mini van, paddy-wagon, palimony, rappel, red-eye, schlep, simulcast, } \\
\text { snow job, street smart, valediction, way station, zucchini }\end{array}$ \\
Australianisms & $\begin{array}{l}\text { barbie, bathers, beaut, chunder, cobber, pom (pommy), sheila } \\
\text { Scottish Eng. }\end{array}$ \\
\hline baim, bonny, brae, kirk, lass, loch, sassenach \\
\hline Trademarks
\end{tabular}


TABLE 3

WORDS MARKED WITH CURRENCY

\begin{tabular}{ll}
\hline Currency & Sample Words \\
\hline Old-fashioned & $\begin{array}{l}\text { aviator, boor, buffoon, dishy, gentry, manservant, marriageable, } \\
\text { nosegay, parson, rattling, salad days, simpleton, vamp, (the) vitals, } \\
\text { wager } \\
\text { bedchamber, damsel, ere, gentlewoman, harlot, hither, methinks, } \\
\text { perchance, quick silver, quoth, thither, thrice, unto, whence }\end{array}$ \\
Old-use & TABLE 4 \\
WORDS MARKED WITH SPECIAL STYLES OR ATTITUDES
\end{tabular}

\begin{tabular}{|c|c|}
\hline Style and attitude & Sample Words \\
\hline Formal Words & $\begin{array}{l}\text { abate, assiduous, avarice, await, capacious, castigate, causality, } \\
\text { chicanery, confabulate, convene, defray, deleterious, elapse, elucidate, } \\
\text { germane, gratuity, gravitate, ignoble, ill-mannered, jurist, lineage, } \\
\text { martinet, nonetheless, obsequies, odious, palliate, ponder, probity, } \\
\text { quiescent, rationale, relinquish, sagacious, salubrious, torpor, tumult, } \\
\text { undue, valediction, vapid, venal, venerate }\end{array}$ \\
\hline Informal Words & $\begin{array}{l}\text { Aussie, backside, baloney, bankable, beefy, bombshell, brainy, butty, } \\
\text { confab, death trap, demo, dicey, diddle, famished, falsies, grey matter, } \\
\text { goofy, icky, junk food, jittery, lifer, mish mash, nab, no place, nose job, } \\
\text { oodles, psycho, rattler (rattle snake), saggy, scoot, scraggly, snooze, } \\
\text { teaser, top-notch, unflappable, veep, wacky, weedy, zit }\end{array}$ \\
\hline Literary Words & $\begin{array}{l}\text { aflame, augury, aureole, baleful, baneful, bard, bedeck, bower, bucolic, } \\
\text { carouse, deflower, dell, glade, halcyon, honeyed, limpid, noonday, } \\
\text { odyssey, paean, philter, quest, ravening, ravish, sequestered, seraphic, } \\
\text { sightless, silken, thrall vanquish, wellspring }\end{array}$ \\
\hline Slang Words & $\begin{array}{l}\text { bollocks, crappy, dick, dick-head, dude, fag, ganja, git, knockers, mule, } \\
\text { pillock, ratarsed, slapper, wuss, yo }\end{array}$ \\
\hline Taboo Words & $\begin{array}{l}\text { coon, cunt, fart, fuck, mother fucker, nigger, prick, pussy, shit, turd, twat, } \\
\text { wank (wanker), whore, yid }\end{array}$ \\
\hline Humorous Words & $\begin{array}{l}\text { beauty sleep, compos mentis, hirsute, impecunious, incorrigible, warpaint, } \\
\text { well-endowed, yokel }\end{array}$ \\
\hline
\end{tabular}

\section{REFERENCES}

[1] Ahmadian, M. Askari, H. (2008). A contrastive analysis of English-Persian dictionaries. Translation studies. 2, 22 : 5-22.

[2] Aryanpur Kashani. M. (1999). The Aryanpur progressive English-Persian dictionary. Tehran: Computer World Co. (Aryanpur)

[3] Bateni. M. R. (2006). The living English-Persian dictionary. Tehran: Farhang Moaser Publishers. (Pouya)

[4] Burkhanov, I. (2003). Pragmatic specifications: usage indications, labels, examples; dictionaries of style, dictionaries of collocations, in P. V. Sterkenburg (Ed.), A practical guide to lexicography. Amsterdam: John Benjamin Publishing Company.

[5] Gove, P. (1967). The dictionary's function: the role of the dictionary. New York: The Bobbs-Merrill Company.

[6] Grenon-Nyenhuis, C. (2000). The dictionary as a cultural institution. International communication studies. 10, 1: 159-166.

[7] Haghshenas, A. M. Samei, H. \& Entekhabi, N. (2003). One Volume Millennium English-Persian Dictionary. Tehran: Farhang Moaser Publishers. (Hezaareh)

[8] Hartmann, R \& James, G. (2002). Dictionary of lexicography. London and New York: Routledge.

[9] Jackson, H. (2002). Lexicography: an introduction. London \& New York: Routledge.

[10] Kipfer, B. (1984). Workbook on lexicography: a course for dictionary users. Exeter: University of Exeter.

[11] Landau, S. I. (2001). Dictionaries: the art and craft of lexicography. Cambridge: Cambridge University Press.

[12] Qaneifard, A. (2003). The challenges of lexicography in Iran. Translation studies, 1, 1: 31-42.

[13] Samei, H. (2000). Bilingual dictionaries: introductory principles. One Volume Millennium English-Persian Dictionary. Tehran: Farhang Moaser Publishers.

[14] Summers, D (2003). Longman dictionary of contemporary English. London: Pearson Education Ltd.

[15] Piotrowski, T. (1994). Problems in bilingual lexicography. Wroclaw: University of Wroclaw.

[16] Svensén, B. (1993). Practical lexicography: principles and methods of dictionary-making. Oxford: Oxford University Press.

[17] Wehmeier, S (2000). Oxford advanced learner's Dictionary. Oxford: Oxford University Press.

[18] Xu, H (2008). Exemplification policy in learners' dictionaries. International journal of lexicography. 21, 4: 395-417.

[19] Yong, H. Peng, J. (2007). Bilingual lexicography from a communicative perspective. Amsterdam: John Benjamin Publishing Company.

[20] Zgusta, L. (1988). Pragmatics, lexicography and dictionaries of English. World Englishes. 7, 3: 243-253. 
Azizollah Dabaghi holds a Ph.D. in TEFL from the University of Auckland, New Zealand. He is an assistant professor at the University of Isfahan, Faculty of Foreign Languages where he teaches graduate and post-graduate courses. His areas of interest are Second Language Acquisition, Teaching English in EFL and ESL Contexts and Translation Studies. He has published and presented a number of articles in these areas. His book, Corrective Feedback in Second Language Acquisition was published by Lambert Academy Publishing in 2010.

Dr. Dabaghi is currently the head of Language Center at the University of Isfahan.

Zohreh Gharaei received her B.A. and M.A. in Translation Studies from the University of Isfahan, Iran. She is presently involved in research on both theoretical and practical aspects of Translation Studies. She is also interested in the issues concerning bilingual lexicography. 